\title{
Performance of hybrid photovoltaic thermal (HPVT) biogas plant
}

\author{
Prabhakant $^{1^{*}}$, Rajeev Kumar Mishra ${ }^{1}$, G.N.Tiwari ${ }^{1}$ \\ ${ }^{1}$ Centre for Energy Studies, Indian Institute of Technology Delhi, New Delhi, India \\ * Corresponding author.Tel: +91 9810651484,Fax:+911126591251,E-mail: prabha.kant@nic.in
}

\begin{abstract}
In this paper, the energy balance equations for the different components of hybrid photovoltaic thermal (HPVT) biogas plant have been written for quasi - steady state conditions to develop a thermal model. An analytical expression for slurry temperature has been obtained as a function of design and climatic parameters namely mass of the slurry, mass flow rate of fluid in collector, number of collectors, solar intensity, ambient temperature etc. Numerical computations have been carried out for climatic conditions of Srinagar, India. Based on mathematical computations it has been observed that the optimum slurry temperature $\left(\sim 37^{\circ} \mathrm{C}\right)$ is achieved for a given set of design parameters of biogas plant and hybrid collectors $\left(\mathrm{M}_{\mathrm{S}}=2000, \dot{m}_{f}=\right.$ $0.05 \mathrm{~kg} / \mathrm{s}, \mathrm{L}=25 \mathrm{~m})$. It has been observed that number of hybrid PVT collector has significant effect on slurry temperature.
\end{abstract}

Keywords: Hybrid PV thermal collector, Thermal modeling, Biogas plants.

\section{Nomenclature}

I(t) Solar intensity at any time $t$. $W m^{-2}$

$T$ temperature..................................... ${ }^{\circ} \mathrm{C}$

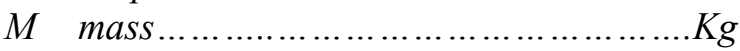

$L \quad$ length of the heat exchanger................m

$N \quad$ number of collectors.............dimensionless

$\dot{m}_{f}$ mass flow rate of water................... $\mathrm{Kgs}^{-1}$

$r_{1} \quad$ Inner radius of the tube in heat exchanger.... $W m^{-2}{ }^{\circ} C^{-1}$

$h$ heat transfer coefficient .............W $m^{-2 o} \mathrm{C}^{-1}$

$\alpha \quad$ absorbitivity of the black absorber plate....

$\alpha \quad$ absorbitivity of the gas holder plate....

$\beta$ temperature coefficient of efficiency

$\tau \quad$ transmittivity of the glass plate.

$h_{1}$ heat transfer coefficient from gas holde plate to gas............................W $\mathrm{Wm}^{-2}{ }^{o} \mathrm{C}^{-1}$

$h_{2}$ heat transfer coefficient from gas holder plate to ambient......................W $\mathrm{m}^{-2 o} \mathrm{C}^{-1}$

$h_{3}$ heat transfer coefficient from gas to slurry .......................Wm ${ }^{-2 o} \mathrm{C}^{-1}$

$h_{c}$ heat transfer coefficient from gas holder to slurry $W m^{-2 o} C^{-1}$

$h_{4}$ heat transfer coefficient from slurry to ground $W m^{-2 o} C^{-1}$

hrps radiative heat transfer coefficient... .......................W $\mathrm{Wm}^{-2}{ }^{o} \mathrm{C}^{-1}$

$T_{\text {so }} \quad$ slurry temp at time $t=0 \ldots \ldots \ldots \ldots \ldots . .{ }^{\circ} \mathrm{C}$

$A_{h} \quad$ horizontal area of the gas holder exposed to solar radiation................................. $m^{2}$

$A v$ veritcal area of the gas holder which is exposed to Solar radiation.................. $m^{2}$

$A h^{\prime}$ vertical area of sulrry........................... ${ }^{2}$

$A_{v}, \quad$ submerged area of gas holder.......... $m^{2}$ $h_{s} \quad$ heat transfer coefficient from tube to slurry ............................Wm ${ }^{-2 o} \mathrm{C}^{-1}$

$U_{l c} \quad$ over all heat transfer coeff... $\ldots . . . . W m^{-2}{ }^{o} C^{-1}$

Subscript

$v$ vertical

$h$ horizontal

o outlet

$i$ inlet

s slurry

a ambient

c solar cell

$p$ plate

$f_{i} \quad$ inlet fluid (water)

$f_{o} \quad$ outlet fluid (water)

$m$ module

g glass 


\section{Introduction}

Biogas is the gas emitted from cow dung in its anaerobic decomposition. Biogas provides fuel for cooking, thus saves the forests and also women from fetching and carrying heavy loads of fuel wood. Biogas is also used for lighting and space heating purpose in rural villages. Thus improves the quality of life. Finally, anaerobic digestion also yields bio-slurry and bio-dregs rich in nutrients, minerals and biologically active compounds. This forms the excellent organic fertilizer for crops and fodder for pig and fish. Production of biogas is maximum when slurry temperature is between 32 to $37^{\circ} \mathrm{C}$.

In order to increase the slurry temperature in harsh cold climatic condition, the researchers have proposed the following techniques:

(i) Erection of canopy green house over the biogas plant [1-6].

(ii) Integration of solar water heater/ solar still with dome [7-10].

(iii)Hot water charging the slurry before fedding into digester [11].

(iv)Integration of flat plate collector to digester through heat exchanger inside slurry, generally referred as active heating [12-15].

In their study, either floating or fixed dome type biogas plant has been considered. On the basis of their finding, it has been concluded that active heating of slurry in digester is more effective in comparison with other heating methods [12-15]. The temperature of slurry can be increased upto optimum level $\left(\sim 37^{\circ} \mathrm{C}\right)$ by optimizing the area of flat plate collector for a given capacity of the slurry. It is further important to mention that only forced mode of operation for thermal heating is viable. Neto et al. [16] have suggested biogas/photovoltaic hybrid power system for decentralized energy supply of rural areas. Also, Dubey and Tiwari [17] have presented a hybrid photovoltaic flat plate collector (hybrid PV water collector) for forced mode to produce electrical as well as thermal energy. If such hybrid PV water is integrated to slurry through heat exchanger as shown in Figure 1a, then one can achieve the following:

(i) Increase in slurry temperature for higher yield in harsh cold climatic condition.

(ii) Hot water for domestic use.

(iii) Electricity production for lighting.

In this case the proposed system can be proved to be more economical than single application in rural area in decentralised manner.

\section{Design of hybrid photovoltaic thermal (HPVT)-biogas Plant:}

There are two types of biogas plat namely floating gasholder type and fixed dome type. In this paper floating gas holder type biogas plant has been considered.

\subsection{Hybrid floating type biogas plant:}

Hybrid photolytic thermal (HPVT)-biogas plant has been shown in the Fig. 1. It consists of (i) a floating type biogas plant; (ii) partially PV covered solar collectors connected in series and (iii) a coil type heat exchanger. Heat exchanger is connected with partially PV covered solar collectors connected in series and is immersed in the slurry as shown in the Fig. 1a. The hot fluid (water) at outlet of hybrid collectors is allowed to flow through heat exchanger and then transferring the heat from heat exchanger to slurry and hence the slurry gets heated. 


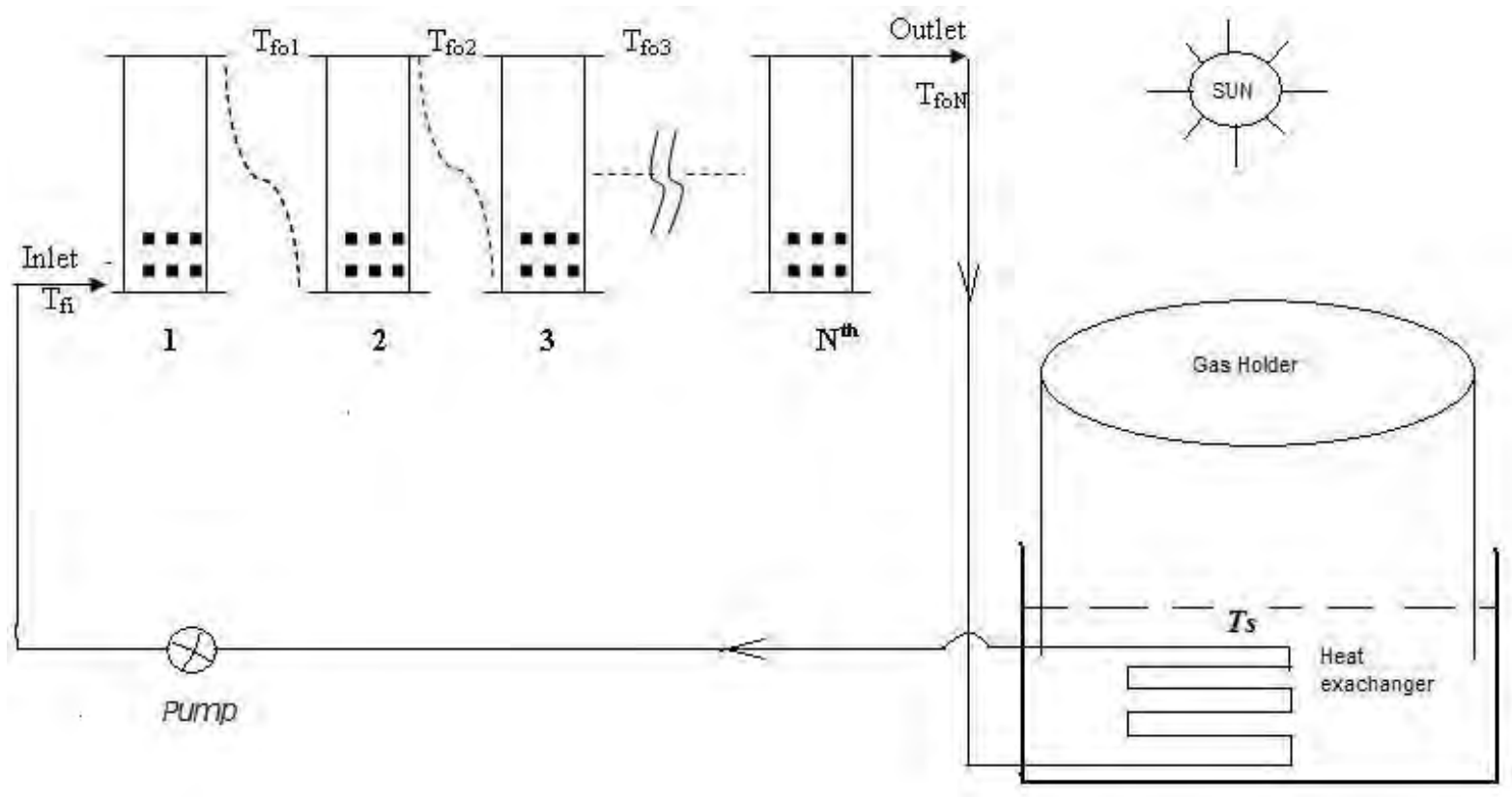

Fig.1 A conventional biogas plant integrated with hybrid PVT solar water collector.

\section{Problem Identification}

In this paper an attempt has been made to optimize the number of partially covered collectors, size of the heat exchanger and mass flow rate of the water in the heat exchanger for a given size of the biogas plant under a given climatic condition.

\section{Thermal Modelling}

\subsection{Assumptions}

In order to write the energy balance equation of hybrid photovoltaic thermal biogas plant, the following assumptions have been made:

- The biogas plant is of floating dome type

- Each component of the system is in quasi - steady state condition

- There is no stratification along the depth of the slurry and the gas column

- Thermal capacity digester and dome of the biogas plant has been neglected

\subsection{Energy Balance Equations}

The energy balance equations during sunshine hours have been formulated as follows.

For gas holder:

$\alpha^{\prime}\left[A_{h} I(t)+I(t)_{v} \frac{A_{v}}{2}\right]=h_{1} A_{t}\left(T_{p}-T_{g}\right)+h_{r p s} A_{h}\left(T_{p}-T_{a}\right)+A^{\prime}{ }_{v} h_{c}\left(T_{p}-T_{s}\right)+h_{2}(t) A_{t}\left(T_{p}-T_{a}\right)$

For biogas: $\quad h_{1} A_{t}\left(T_{p}-T_{g}\right)=h_{3} A_{h}\left(T_{g}-T_{s}\right)$

For slurry: 


$$
\begin{aligned}
M_{s} C_{s} \frac{d T_{s}}{d t}= & h_{3} A_{h}\left(T_{g}-T_{s}\right)+A_{h} h_{r p s}\left(T_{p}-T_{s}\right)+A_{v}^{\prime} h_{c}\left(T_{p}-T_{s}\right) \\
& -h_{4} A_{h}\left(T_{s}-T_{\infty}\right)-h_{s a} A_{h}^{\prime}\left(T_{s}-T_{a}\right)-A_{h}^{\prime} \dot{Q}_{e s}+\dot{Q}_{u}
\end{aligned}
$$

where,

$$
\dot{Q}_{e s}=h_{e w}\left(T_{s}-T_{a}\right)
$$

(4)

and,

$$
h_{e w}=\frac{0.016 h_{s a}\left\{P\left(\bar{T}_{s}\right)-\gamma P\left(\bar{T}_{a}\right)\right\}}{\left(\bar{T}_{s}-\bar{T}_{a}\right)} .
$$

Now, the rate of heat transfer from flowing fluid in the heat exchanger to the slurry can be written as

$$
\begin{aligned}
\dot{Q}_{u} & =U 2 \pi r_{1} L\left(\bar{T}_{w}-T_{s}\right) \\
& =\dot{m}_{f} c_{f}\left(1-\exp \left(-\frac{2 \pi r_{1} U}{\dot{m}_{f} c_{f}} L\right)\right)\left(T_{f o N}-T_{s}\right)
\end{aligned}
$$

Following Dubey and Tiwari [4], for N identical collectors partially covered by PV modules connected in series, the outlet fluid temperature at the end of $\mathrm{N}^{\text {th }}$ collector can be given as,

$$
T_{f \circ N}=\frac{\left(A F_{R}(\alpha \tau)\right)_{1}}{\dot{m}_{f} C_{f}}\left(\frac{1-K_{K}^{N}}{1-K_{K}}\right) I(t)+\frac{\left(A F_{R} U_{L}\right)_{1}}{\dot{m}_{f} C_{f}}\left(\frac{1-K_{K}^{N}}{1-K_{K}}\right) T_{a}+T_{f} i K_{K}^{N}
$$

With the help of Eqs (4) \& (5) , Eq (3) can be solved for the slurry temperature

\subsection{Electrical output:}

The electrical output generated by proposed hybrid photovoltaic thermal biogas can be evaluated by the following expression

$$
E_{\text {daily }}=\sum_{i=1}^{n} \eta_{m} \times I_{i} \times A_{m} \times N
$$

where,

$$
\eta_{m}=\eta_{m o}\left[1-\beta\left(\bar{T}_{f}-T_{a}\right)\right], \quad \bar{T}_{f}=\frac{T_{f O N}+T_{f i}}{2}, \quad \eta_{m o}=0.12 \text { and } \beta=0.0045 .
$$

\subsection{Thermal output:}

The rate of thermal energy available from the proposed hybrid photovoltaic thermal biogas plant can be obtained as:

$$
\dot{q}_{u}=\dot{m}_{f} \dot{c}_{f}\left(T_{f O N}-T_{f i}\right)
$$


The daily thermal energy is given by

$$
Q_{u}=\sum_{i=1}^{n} \dot{q}_{u i} ; \quad \text { n is sunshine hour. }
$$

The daily exergy is given by

$$
E x_{\text {daily }}=Q_{u}\left[1-\frac{\bar{T}_{a}+273}{\bar{T}_{f O N}+273}\right]
$$

For a set of design and climatic parameters, outlet temperature of $n^{\text {th }}$ collector and Slurry temperature has been calculated using MATLAB software.

\section{Results and discussions}

Hourly variation of solar intensity on the horizontal and vertical walls of the dome has been calculated by using Liu and Jordan formula with the help MATLAB software. Fig. 2 shows the variation of solar intensity and ambient air temperature with time. Fig 3 gives the variation of outlet temperature from $\mathrm{N}^{\text {th }}$ collector and slurry temperature during 24 hours period of day and night. Figure shows that there is increase in slurry temperature $\left(T_{s}\right)$ with time of the day as more thermal energy is available from hybrid PVT collectors. It attains maximum temperature $\left(\mathrm{T}_{\mathrm{smax}}\right)$ of about $30^{\circ} \mathrm{C}$ at $4 \mathrm{pm}$ due to heat capacity of the slurry. This temperature can be further increased by decreasing the mass of the slurry. Further, it is to be noted that the outlet fluid temperature is achieved upto about $80-90^{\circ} \mathrm{C}$ at noon time as expected. Fig. 4 shows the variation of peak slurry temperature $\left(T_{\text {smax }}\right)$ with mass flow rate. The peak slurry temperature $\left(\mathrm{T}_{\mathrm{smax}}\right)$ increases rapidly with increase of mass flow rate of the fluid due to fast transfer of heat into the slurry. It is observed that there is not much variation in peak slurry temperature $\left(T_{\text {smax }}\right)$ after mass flow rate $0.05 \mathrm{~kg} / \mathrm{s}$ and hence one can conclude that the optimum mass flow rate is $0.05 \mathrm{~kg} / \mathrm{s}$ for design parameters given in Table 1 and climatic parameters shown in Fig. 2. Fig.5 shows the variation of peak slurry temperature $\left(T_{\text {smax }}\right)$ with the mass of the slurry $\left(M_{s}\right)$. This figure shows that peak slurry temperature $\left(T_{\text {smax }}\right)$ decreases with increase of the mass of the slurry $\left(M_{s}\right)$. It is observed that for the given design and climatic parameters, the optimum mass of the slurry is $2000 \mathrm{~kg}$. The variation of peak slurry temperature $\left(\mathrm{T}_{\text {smax }}\right)$ with number of $\mathrm{PV} / \mathrm{T}$ collectors $\mathrm{N}$ is shown in Fig.6. This figure shows that peak slurry temperature $\left(T_{\text {smax }}\right)$ also increases with increase of number of collectors due to increase of thermal energy provided by PVT collectors to the slurry. It is observed that there is not much variation in peak slurry temperature $\left(T_{\text {smax }}\right)$ after 50 numbers of collectors and hence the optimum number of collectors for a design and climatic parameters under consideration is about 50 .

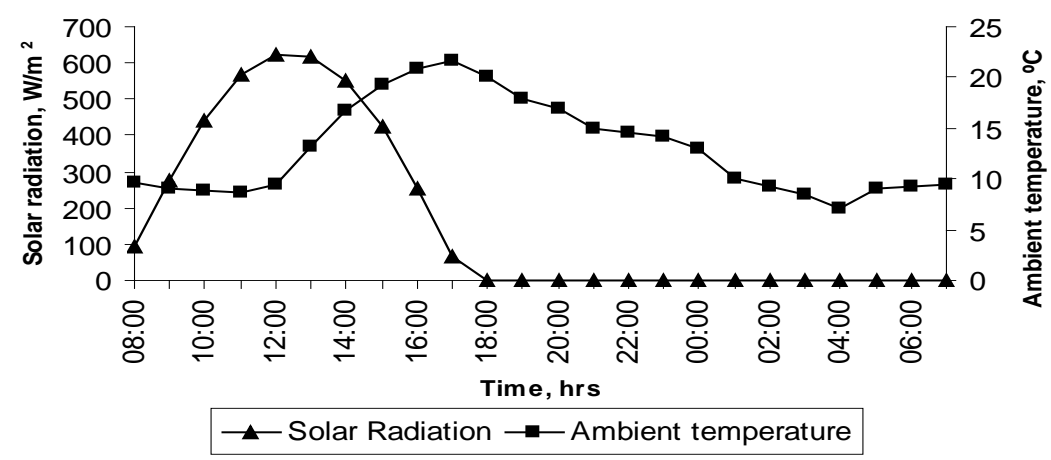

Fig.2. Variation of solar intensity and ambient temperature with time. 


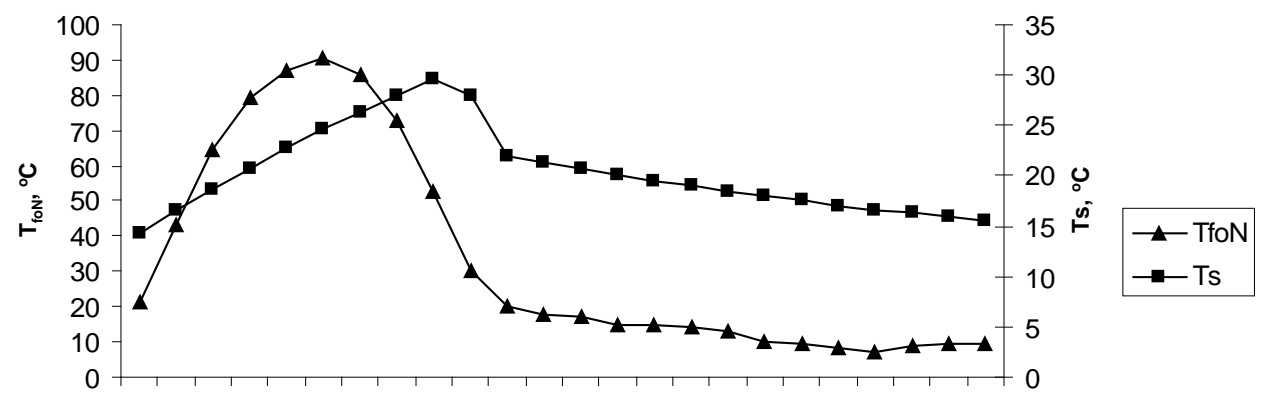

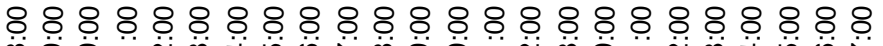

边

Time, hrs

Fig.3. Variation of outlet water temperature $\left(T_{f o N}\right)$ and slurry temperature $\left(T_{s}\right)$ with time

$$
\left(M_{S}=2500, \quad \dot{m}_{f}=0.02 \mathrm{~kg} / \mathrm{s}, L=25 \mathrm{~m}, N=40\right)
$$

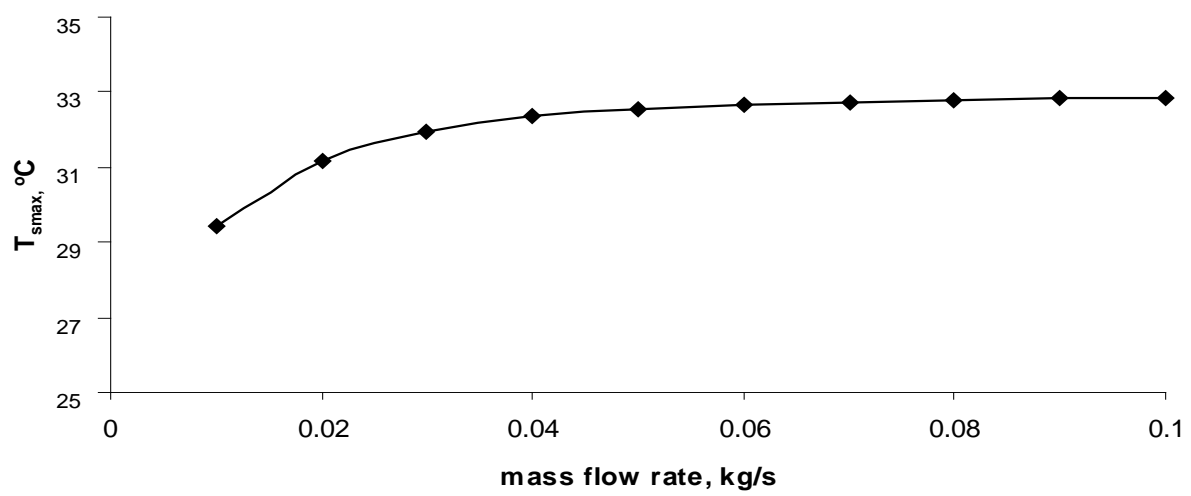

Fig.4. Variation of maximum slurry temperature with mass flow rate of the slurry.

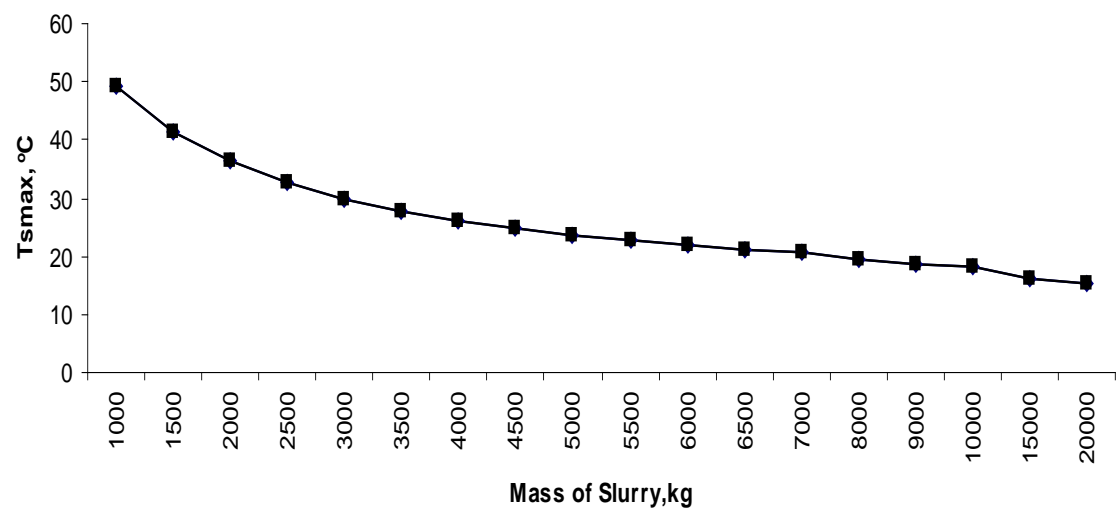

Fig.5: Variation of maximum slurry temperature with mass of slurry for $N=40$ and mass flow rate $=0.02 \mathrm{~kg} / \mathrm{s}$. 


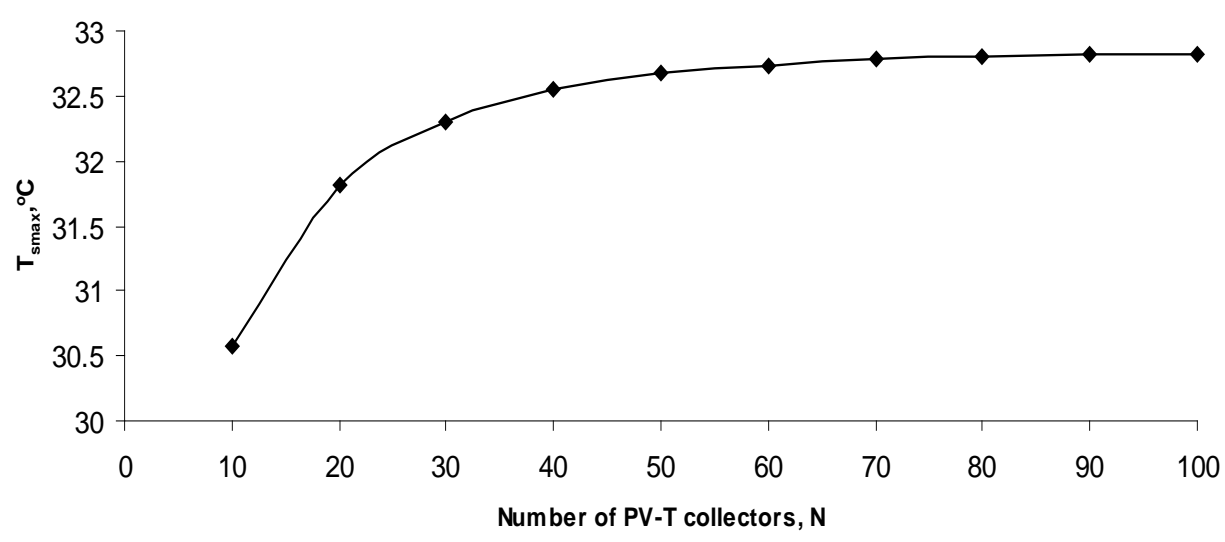

Fig.6. Variation of maximum slurry temperature with number of $P V$-T water collectors.

\section{Conclusions}

On the basis of present studies, one can conclude that:

(i) The design parameter of PVT integrated biogas plant can be optimised for a given capacity by using the present thermal model.

(ii) The present system is most suitable and self sustainable for cold climatic condition where ambient air temperature is much less than the optimum operating temperature $\left(\sim 37^{\circ} \mathrm{C}\right)$ of the biogas plant.

\section{References}

[1] M.S. Sodha, S. Ram, N. K. Bansal and P. K. Bansal. Effect of PVC greenhouse in increasing the biogas production in temperate cold climatic conditions. Energy Conversion and Management 1987; 27 (1): 83-90.

[2] K. Vinoth Kumar , R. Kasturi Bai Solar greenhouse assisted biogas plant in hilly region - A field study, Solar Energy. 2008; 82: 911-917.

[3] N.K. Bansal, S.C. Bhand, S. Ram and K. K. Singh. A study of a greenhouse concept on conventional biogas systems for enhancing biogas yield in winter months. International Journal Energy Resources. 1985; 9: 119-128.

[4] M. Dayal, K.K.Singh, P.K. Bansal and S. Ram Solar assisted biogas digesters I: thermal analysis. International Journal Energy Resources 1985; 9: 455-462.

[5] K. Vinoth Kumar , R. Kasturi Bai Solar greenhouse assisted biogas plant in hilly region - A field study, Solar Energy. 2008; 82: 911-917.

[6] J.A.Usmani, G.N.Tiwari and Avinash Chandra. Performance Characteristic of a greenhouse integrated biogas system. Energy Conservation and Management 1996; 37(9):1423-1433.

[7] A. Kumar, N. Reddy, C.R. Prassad, P. Rajabapaiah, S.R.C. Satyanarayan.. Studies in biogas technology Part II - A novel biogas plant incorporating a solar water heater and solar water hater and solar still. Proceedings of Indian Academy of Sciences C2 (Part-3). 1979; 387-393. 
[8] A.K.N. Reddy, C.R. Prasad, P. Rajabapaiah, S.R. Sathyanarayan. Studies in biogas technology, Part IV. A novel biogas plant incorporating solar water heater and solar still. Proceedings of Indian Academic Science. 1979;C2: 387-393.

[9] D. Singh, K.K. Singh, N.K. Bansal. Heat loss reduction from the gas holder/fixed gas dome of a community-size biogas plant. International Journal Energy Resources. 1985; 9: 417-430.

[10] G.N.Tiwari, A. Chandra. Solar assisted biogas systems: a new approach. Energy Conversion and Management 1986; 26 (2): 147-150.

[11]D.J. Hills, J.R. Stephens. Solar energy heating of dairy-manure anaerobic digesters. Agricultural Wastes. 1980; 2 (2):103-118.

[12] G. N. Tiwari, S. K. Singh and Kailash Thakur. Design criteria for an active biogas plant. Energy 1992; 17(10):955-958.

[13] G.N. Tiwari. Enhancement in daily production of biogas systems. Energy Conversion and Management. 1986; 26 (3/4), 379-382.

[14] G. N. Tiwari, S. B. Sharma and S. P. Gupta. Transient performance of a horizontal floating gas holder type biogas plant. Energy Conversion and Management. 1988; 28(3): 235-239.

[15] A. Axaopoulos and P. Panagakis, Energy and Economics analysis of biogas heated livestock building, Biomass and Bioenergy, 2003,24,239-248.

[16] M.R.Borges Neto, P.C.M. Carvalho, J.O.B. Carioca, F.J.F. Canafi’s stula, Biogas/ Phtotvotaic hybrid power system for decentralized energy supply of rural areas, Energy Policy 2010; 38: 4497-4506.

[17] Prabhakant and G. N. Tiwari. Analysis of Return on Capital for Bio Gas Plants with and without Embodied Energy. Journal of Energy Storage and Conversion, Jan-June. 2009; 1: 61-78. 